\title{
Genetic Algorithm based Multiobjective Optimal Power Dispatch based on Ideal Distance Minimization
}

\author{
${ }^{1}$ Mamta, ${ }^{2}$ U. Nangia, ${ }^{3}$ N. K. Jain \\ ${ }^{2,3}$ Electrical Engineering Department,Delhi Technological University, Bawana Road, New Delhi-110042, India \\ ${ }^{1}$ Electrical Engineering Department, Bipin Tripathi Kumaon Institute Technology (Uttarakhand Technical \\ University), Dwarahat, Almora-263653, Uttarakhand, India
}

\begin{abstract}
In this paper, the cost of generation and system transmission losses have been considered as objectives for optimization. The multiobjective optimal power dispatch (MOPD) problem is formulated using weighting method and a number of noninferior solutions are generated in $2 D$ space by varying weights for IEEE 5, 14 and 30 bus systems - manually using GA technique, by using GA toolbox of MATLAB R2008b. Ideal Distance minimization method has been used to obtain the optimal power system operation (Target Point, best compromise solution). This method employs the concept of an 'Ideal Point' (IP) to scalarize the problems having multiple objectives and minimizes the Euclidean distance between IP and a set of noninferior solutions.
\end{abstract}

Keywords: Multiobjective Optimal Power Dispatch, weighting method, 2D space, Genetic Algorithm (GA).

\section{Introduction}

Economic load dispatch is most efficient, low cost and reliable operation of a power system by dispatching the available electricity generation resources to the load on the system. The primary objective of economic dispatch is to minimize the total fuel cost of generation while honoring the operational constraints of the available generation resources.

Multiobjective optimization (or programming), $[1,2,3]$ also known as multi-criteria or multi-attribute optimization, is the

process of simultaneously optimizing two or more conflicting objectives subject to certain constraints.

In single objective optimization methods, the analyst can make only one suggestion. In case it is not acceptable to the management and the decision making process gets stuck up. This is not the case with multiobjective approach as analyst has a number of alterative suggestion, one of which the management has to choose one.

The way out, therefore lies in the multiobjective approach $[4,5]$ to problem solving. The solution of multiobjective optimization gives a number of solutions called noninferior solutions. In this paper, the objectives considered for optimal power dispatch are - cost of generation $\left(\mathrm{F}_{\mathrm{C}}\right)$ and transmission losses $\left(\mathrm{F}_{\mathrm{L}}\right)$.

The economic dispatch problem is to minimize the overall generating cost which is the function of plant output given by

$\mathrm{F}_{\mathrm{C}}\left(\mathrm{P}_{\mathrm{i}}\right)=\Sigma \mathrm{a}_{\mathrm{i}} \mathrm{P}_{\mathrm{i}}^{2}+\mathrm{b}_{\mathrm{i}} \mathrm{P}_{\mathrm{i}}+\mathrm{c}_{\mathrm{i}} \quad(\mathrm{i}=1,2, \ldots \ldots, \mathrm{NG})$

Where

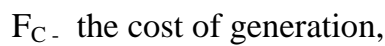

$\mathrm{P}_{\mathrm{i}}$ - Real power generation and is the decision variable

$a_{i}, b_{i}, c_{i}-$ cost coefficients

Subject to the constraints that generation should equal total demand plus losses, i.e.

$\Sigma \mathrm{P}_{\mathrm{i}}=\mathrm{P}_{\mathrm{D}}+\mathrm{P}_{\mathrm{L}}$ 
$P_{D}-$ Power demand of generating plant, $P_{L}-$ power losses of generating plant

Satisfying the inequality constraints, expressed as follows:

$\mathrm{P}_{\mathrm{i}(\max )} \leq \mathrm{P}_{\mathrm{i}} \leq \mathrm{P}_{\mathrm{i}(\min )} \quad(i=1,2, \ldots \ldots, \mathrm{NG})$

Where $\mathrm{P}_{\mathrm{i}(\min )}$ and $\mathrm{P}_{\mathrm{i}(\max )}$ are the minimum and maximum generating limits respectively, for $\mathrm{i}^{\text {th }}$ plant.

The ideal situation where one would like to operate the power systems is one where all the objectives are minimize. But this is not feasible due to conflicting nature of objectives. Therefore, one can achieve a point which is noninferior and at the minimum distance from the ideal point. Such a point is known as the Target Point (TP) or the best compromise solution.

The multiobjective techniques give us a number of non-inferior solutions, all of which are candidates for optimal solution. In this paper, the weighting method [6] using GA technique is used to generating the noninferior solutions in 2D space of IEEE 5, 14, and 30 bus systems. Such analysis, the power system operation point can be determined. The distance of all the feasible operating points (noninferior solutions) from the ideal power system operation point is calculated and the optimal power system operation is one for which this distance is minimum. This method directly gives the best compromise solution.

\section{Tool (GA tool) in MATLAB}

Our objective in this work is to solve multiobjective optimal power dispatch (MOPD) problem by using minimum distance method with the help of GA tool. Genetic algorithm software extends the optimization capabilities in MATLAB R2008b optimization toolbox. GA tool uses these algorithms for problems that are difficult to solve with traditional optimization techniques, including problems that are not well defined or are difficult to model. Mathematically, GA is also used when computation of the objective function is discontinuous, highly nonlinear, stochastic, or has unreliable or undefined derivatives.

\section{Formulation of MOPD Problem}

Two aspects of the optimal power dispatch (OPD) problem considered in 2D space are:

(i) To minimize the cost of generation.

(ii) To minimize the system transmission losses.

The objective function to minimize the cost of generation is given as

$$
\mathrm{F}_{\mathrm{C}}=\sum_{\mathrm{i}=1}^{\mathrm{NG}}\left[\mathrm{C}_{\mathrm{i}}\left(\mathrm{P}_{\mathrm{gi}}\right)\right] \quad(\mathrm{i}=1,2, \ldots \ldots, \mathrm{NG})
$$

Where $\mathrm{P}_{\mathrm{gi}}$ is the power generation at the ith generator, $\mathrm{C}_{\mathrm{i}}$ is the cost of generation for $\mathrm{i}^{\text {th }}$ generator and $\mathrm{NG}$ is the total number of generators in the system.

The objective function to minimize the system transmission losses is defined as:

$\mathrm{F}_{\mathrm{L}}=\Sigma \Sigma \mathrm{P}_{\mathrm{i}} \mathrm{B}_{\mathrm{ij}} \mathrm{P}_{\mathrm{j}}$

Where, $\quad B_{i j}=$ Loss coefficients.

$\mathrm{i}=1,2, \ldots \ldots, \mathrm{NG}$

$\mathrm{j}=1,2, \ldots \ldots, \mathrm{NG}$

$\mathrm{NG}=$ the number of generators 


\section{Ideal distance minimization method}

This method [7] employs the concept of an 'Ideal Point' (IP). It's scalarized the problems having multiple objectives and minimizes the Euclidean distance between the IP and the set of feasible or noninferior solutions.

In 2D space, the multiobjective function comprises of cost of generation and system transmission losses i.e.

$$
\mathrm{F}=\left[\mathrm{F}_{\mathrm{C}}, \mathrm{F}_{\mathrm{L}}\right]
$$

To generate the noninferior solution of multiobjective optimization problem, the weighting method is used. In this method the problem is converted into a scalar optimization problem as Minimize $\mathrm{F}=\mathrm{W}_{\mathrm{C}} \mathrm{F}_{\mathrm{C}}+\mathrm{W}_{\mathrm{L}} \mathrm{F}_{\mathrm{L}}$

Where

$\mathrm{F}_{\mathrm{C}}$ is the cost of generation.

$\mathrm{W}_{\mathrm{C}}$ is the weight attached to cost of generation.

$\mathrm{F}_{\mathrm{L}}$ is the system transmission loss.

$\mathrm{W}_{\mathrm{L}}$ is the weight attached to system transmission losses.

The ideal situation where one would like to operate the power system is the one where both objectives namely cost of generation $\left(\mathrm{F}_{\mathrm{C}}\right)$ and system transmission loss $\left(\mathrm{F}_{\mathrm{L}}\right)$ are minimum. In $2 \mathrm{D}$ space, the point having coordinator $\left(\mathrm{F}_{\mathrm{Cmin}}, \mathrm{F}_{\mathrm{Lmin}}\right)$ represents the Ideal Point (IP). In order to locate Target Point in 2D space, the following distance function is proposed:

Distance $=\left[\left(\mathrm{F}_{\mathrm{C}}-\mathrm{F}_{\mathrm{C} \min }\right)^{2}+\left(\mathrm{F}_{\mathrm{L}}-\mathrm{F}_{\mathrm{Lmin}}\right)^{2}\right]^{1 / 2}$

Where

$\mathrm{F}_{\mathrm{Cmin}}-$ The value of cost of generation obtained by individually minimizing $\mathrm{F}_{\mathrm{C}}$.

$\mathrm{F}_{\mathrm{Lmin}}$ - The value of system transmission losses obtained by individually minimizing $\mathrm{F}_{\mathrm{L}}$.

\section{Results}

The noninferior set is generated in 2D space by varying the weights attached to the objective function defined by equation (7). It is shown in Tables 1, 2, and 3 for IEEE 5-bus, 14-bus and 30-bus systems respectively.

It is observed that the range of transmission losses is very small compared to that of cost of generation. Therefore, the range of system transmission losses has been multiplied by the ratio $R_{C} / R_{L}$ which makes the range of system transmission losses numerically almost equal to that of cost of generation.

Where

$\mathrm{R}_{\mathrm{C}}=$ range of cost of generation $=\mathrm{F}_{\text {CatFLmin }}-\mathrm{F}_{\mathrm{Cmin}}$

$\mathrm{R}_{\mathrm{L}}=$ Range of system transmission losses $=\mathrm{F}_{\text {LatFemin }}-\mathrm{F}_{\mathrm{Lmin}}$

$\mathrm{F}_{\mathrm{Cmin}}$ - The value of cost generation obtained by individually minimizing $\mathrm{F}_{\mathrm{C}}$.

$\mathrm{F}_{\mathrm{Lmin}}$ - The value of system transmission losses obtained by individually minimizing $\mathrm{F}_{\mathrm{L}}$.

$\mathrm{F}_{\mathrm{CatFLmin}}$-The value of cost generation obtained by individually minimizing $\mathrm{F}_{\mathrm{L}}$.

$\mathrm{F}_{\text {LatFemin }}$ - The value of system transmission losses obtained by individually minimizing $\mathrm{F}_{\mathrm{C}}$

\subsection{Distance function for IEEE 5-bus system:}

From Table -1 , it is observed that

$\mathrm{R}_{\mathrm{C}}=763.1833-760.951=2.2323$

$\mathrm{R}_{\mathrm{L}}=5.1812-5.0582=0.1230$ 
$\mathrm{R}_{\mathrm{C}} / \mathrm{R}_{\mathrm{L}}=18.14$

The distance function for 5-bus is

Distance $1=\left[\left(\mathrm{F}_{\mathrm{C}}-\mathrm{F}_{\mathrm{Cmin}}\right)^{2}+18.14 *\left(\mathrm{~F}_{\mathrm{L}}-\mathrm{F}_{\mathrm{Lmin}}\right)^{2}\right]^{1 / 2}$

The distance of each of the noninferior point is calculated by equation (9) and the result is shown in the last column of Table-1.

Table-1Results of MOPD studies by varying weights in 2D space (IEEE 5-bus system)

\begin{tabular}{|c|c|c|c|c|c|}
\hline S.No. & $\mathbf{W}_{\mathbf{C}}$ & $\mathbf{W}_{\mathbf{L}}$ & $\mathbf{F}_{\mathbf{L}}$ & $\mathbf{F}_{\mathbf{C}}$ & distance \\
\hline 1 & 0 & 1 & 5.0582 & 763.1833 & 0.022323 \\
\hline 2 & 1 & 0 & 5.1812 & 760.951 & 0.022324 \\
\hline 3 & 1 & 0.01 & 5.1811 & 760.9597 & 0.022307 \\
\hline 4 & 1 & 0.05 & 5.1805 & 760.9628 & 0.022198 \\
\hline 5 & 1 & 0.1 & 5.1798 & 760.9614 & 0.022071 \\
\hline 6 & 1 & 0.5 & 5.1745 & 760.9595 & 0.021109 \\
\hline 7 & 1 & 1 & 5.1684 & 760.9644 & 0.020002 \\
\hline 8 & 1 & 10 & 5.1088 & 761.2431 & 0.009637 \\
\hline$\underline{9}$ & $\underline{1}$ & $\underline{20}$ & $\underline{5.0856}$ & $\underline{761.57}$ & $\underline{0.00794}$ \\
\hline 10 & 1 & 30 & 5.0753 & 761.8217 & 0.009244 \\
\hline 11 & 1 & 40 & 5.0699 & 762.0106 & 0.010807 \\
\hline 12 & 1 & 50 & 5.0667 & 762.1547 & 0.012135 \\
\hline 13 & 1 & 60 & 5.0647 & 762.2672 & 0.013215 \\
\hline 14 & 1 & 70 & 5.0633 & 762.3545 & 0.014065 \\
\hline 15 & 1 & 80 & 5.0623 & 762.4329 & 0.014838 \\
\hline 16 & 1 & 90 & 5.0615 & 762.4886 & 0.015388 \\
\hline 17 & 1 & 100 & 5.061 & 762.5433 & 0.015931 \\
\hline 18 & 10 & 0.01 & 5.1811 & 760.9597 & 0.022307 \\
\hline 19 & 10 & 0.05 & 5.1811 & 760.9597 & 0.022307 \\
\hline 20 & 10 & 0.1 & 5.181 & 760.9601 & 0.022288 \\
\hline 21 & 10 & 0.5 & 5.181 & 760.9604 & 0.022288 \\
\hline 22 & 10 & 1 & 5.1797 & 760.9615 & 0.022052 \\
\hline 23 & 10 & 10 & 5.1684 & 760.9644 & 0.020002 \\
\hline 24 & 10 & 20 & 5.1577 & 760.984 & 0.018062 \\
\hline 25 & 10 & 30 & 5.1483 & 761.0039 & 0.016362 \\
\hline 26 & 10 & 40 & 5.1403 & 761.0321 & 0.014923 \\
\hline 27 & 10 & 50 & 5.1333 & 761.0637 & 0.013677 \\
\hline 28 & 10 & 60 & 5.1271 & 761.0982 & 0.012592 \\
\hline 29 & 10 & 70 & 5.1217 & 761.1353 & 0.011672 \\
\hline 30 & 10 & 80 & 5.1169 & 761.1704 & 0.010878 \\
\hline 31 & 10 & 90 & 5.1126 & 761.2036 & 0.010192 \\
\hline 32 & 10 & 100 & 5.1087 & 761.2392 & 0.009608 \\
\hline & & & & & \\
\hline
\end{tabular}


Noninferior set for IEEE 5-bus has been shown in graph of Fig.1. It has been plotted from Table-1 between transmission loss function (as $\mathrm{X}$ - axis) and cost of generation function (Y-axis). IP shows the Ideal Point which is infeasible and TP shows the Target Point or the best compromise solution which is at minimum distance from Ideal Point.

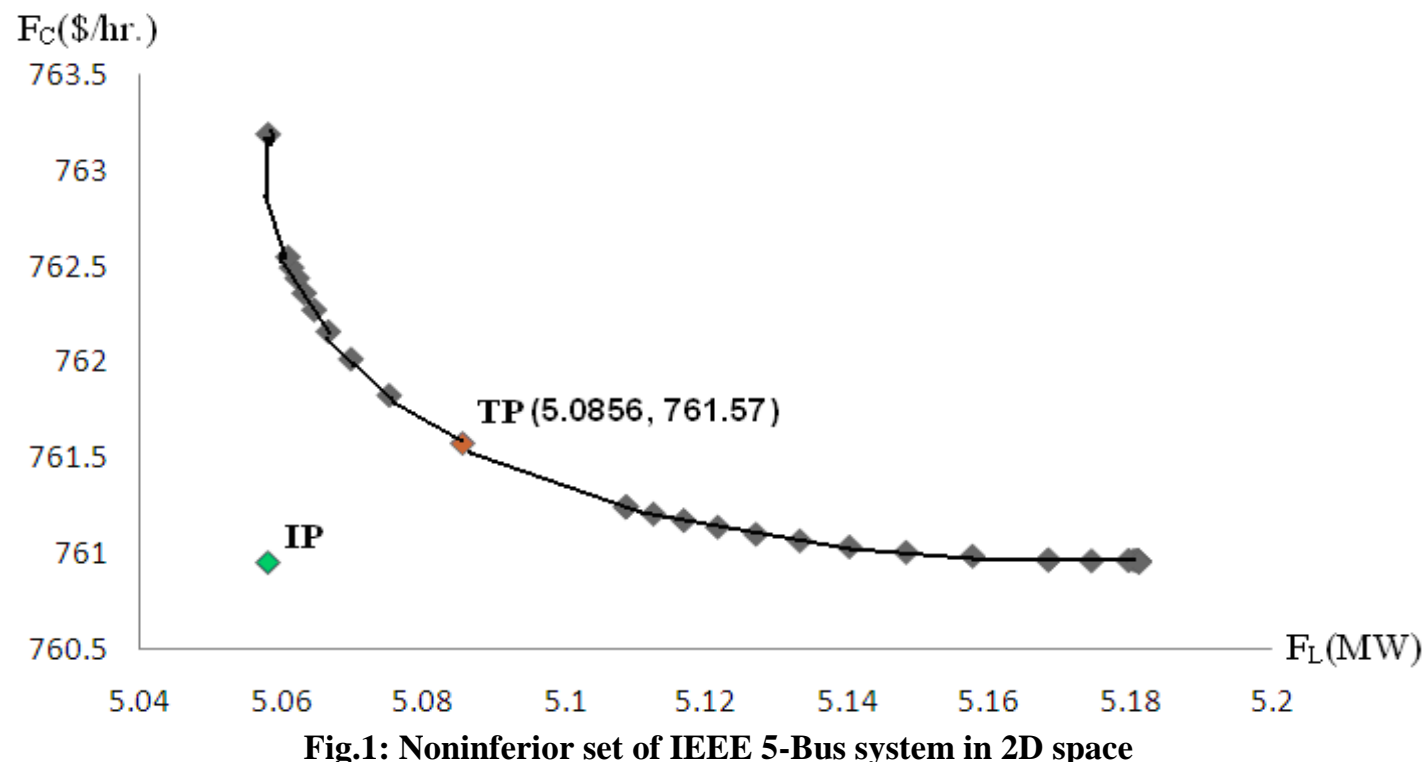

It is observed from the graph that at Target Point:

Cost of generation is $\mathrm{F}_{\mathrm{C}} *=761.57 \$ / \mathrm{hr}$

Transmission losses is $\mathrm{F}_{\mathrm{L}} *=5.0856 \mathrm{MW}$

Hence the Target Point is $\left(\mathrm{F}_{\mathrm{C}} *, \mathrm{~F}_{\mathrm{L}}{ }^{*}\right)$ or $(761.57,5.0856)$ and the minimum distance from Ideal Point $(760.9515$, 0.0582) to Target Point $(761.57,5.0856)$ is 0.00794 . It is shown at S.No. 9 of Table-1.

\subsection{Distance function for IEEE 14-bus system:}

From Table-2, it is observed that

$\mathrm{R}_{\mathrm{C}}=1189-1137.5=51.5$

$\mathrm{R}_{\mathrm{L}}=8.7-7.4=1.3$

$\mathrm{R}_{\mathrm{C}} / \mathrm{R}_{\mathrm{L}}=39.62$

The distance function for 14-bus is

Distance $=\left[\left(\mathrm{F}_{\mathrm{C}}-\mathrm{F}_{\mathrm{Cmin}}\right)^{2}+39.62 *\left(\mathrm{~F}_{\mathrm{L}}-\mathrm{F}_{\mathrm{Lmin}}\right)^{2}\right]^{1 / 2}$

The distance of each of the noninferior point is calculated by (10) and the result is shown in the last column of Table-2.

Table-2 Results of MOPD studies by varying weights in 2D space (IEEE 14-bus system)

\begin{tabular}{|c|c|c|c|c|c|}
\hline S.No. & $\mathbf{W}_{\mathbf{C}}$ & $\mathbf{W}_{\mathbf{L}}$ & $\mathbf{F}_{\mathbf{L}}$ & $\mathbf{F}_{\mathbf{C}}$ & distance \\
\hline 1 & 0 & 1 & 7.4 & 1189 & 0.515 \\
\hline 2 & 1 & 0 & 8.7 & 1137.5 & 0.5151 \\
\hline 3 & 1 & 0.01 & 8.7 & 1137.5 & 0.5151 \\
\hline 4 & 1 & 0.05 & 8.7 & 1137.5 & 0.5151 \\
\hline 5 & 1 & 1 & 8.6 & 1137.8 & 0.4754 \\
\hline 6 & 1 & 5 & 8.6 & 1137.8 & 0.4754 \\
\hline 7 & 1 & 10 & 8.4 & 1139.6 & 0.3968 \\
\hline 8 & 1 & 20 & 8 & 1142.1 & 0.2421 \\
\hline 9 & 1 & 25 & 7.9 & 1144.6 & 0.2104 \\
\hline
\end{tabular}




\begin{tabular}{|l|l|l|l|l|l|}
\hline$\underline{\mathbf{1 0}}$ & $\underline{\mathbf{1}}$ & $\underline{\mathbf{4 0}}$ & $\underline{\mathbf{7 . 7}}$ & $\underline{\mathbf{1 1 5 2 . 8}}$ & $\underline{\mathbf{0 . 1 9 3 7}}$ \\
\hline 11 & 1 & 55 & 7.6 & 1157.5 & 0.2179 \\
\hline 12 & 1 & 60 & 7.6 & 1158.8 & 0.2273 \\
\hline 13 & 1 & 90 & 7.5 & 1164.8 & 0.2759 \\
\hline 14 & 1 & 95 & 7.5 & 1165.6 & 0.2838 \\
\hline 15 & 10 & 0 & 8.7 & 1137.5 & 0.5151 \\
\hline 16 & 10 & 1 & 8.7 & 1137.5 & 0.5151 \\
\hline 17 & 10 & 0.01 & 8.7 & 1137.5 & 0.5151 \\
\hline 18 & 10 & 0.05 & 8.7 & 1137.5 & 0.5151 \\
\hline 19 & 10 & 0.1 & 8.7 & 1137.5 & 0.5151 \\
\hline 20 & 10 & 0.5 & 8.7 & 1137.5 & 0.5151 \\
\hline 21 & 10 & 1 & 8.7 & 1137.5 & 0.5151 \\
\hline 22 & 10 & 5 & 8.7 & 1137.5 & 0.5151 \\
\hline 23 & 10 & 10 & 8.7 & 1137.5 & 0.5151 \\
\hline 24 & 10 & 15 & 8.7 & 1137.5 & 0.5151 \\
\hline 25 & 10 & 20 & 8.7 & 1137.5 & 0.5151 \\
\hline 26 & 10 & 25 & 8.7 & 1137.5 & 0.5151 \\
\hline 27 & 10 & 30 & 8.7 & 1137.5 & 0.5151 \\
\hline 28 & 10 & 35 & 8.7 & 1137.5 & 0.5151 \\
\hline 29 & 10 & 45 & 8.6 & 1137.7 & 0.4754 \\
\hline 30 & 10 & 50 & 8.6 & 1137.8 & 0.4754 \\
\hline 31 & 10 & 55 & 8.6 & 1137.9 & 0.4755 \\
\hline 32 & 10 & 60 & 8.6 & 1138 & 0.4358 \\
\hline 33 & 10 & 65 & 8.6 & 1138.1 & 0.4755 \\
\hline 34 & 10 & 70 & 8.5 & 1138.2 & 0.4359 \\
\hline 35 & 10 & 75 & 8.5 & 1138.5 & 0.4359 \\
\hline 36 & 10 & 80 & 8.5 & 1138.7 & 0.436 \\
\hline 37 & 10 & 85 & 8.5 & 1138.9 & 0.436 \\
\hline 38 & 10 & 90 & 8.4 & 1139.2 & 0.3966 \\
\hline 39 & 10 & 95 & 8.4 & 1139.4 & 0.3967 \\
\hline 40 & 10 & 100 & 8.4 & 1139.6 & 0.3968 \\
\hline
\end{tabular}


Noninferior set for IEEE 14-bus has been shown in graph of Fig.2. It has been plotted from Table-2 between transmission loss function (as $\mathrm{X}$ - axis) and cost of generation function (Y-axis). IP shows the Ideal Point which is infeasible and TP shows the Target Point or the best compromise solution which is at minimum distance from Ideal Point. $\left(\mathrm{F}_{\mathrm{C}} *, \mathrm{~F}_{\mathrm{L}}{ }^{*}\right)$.

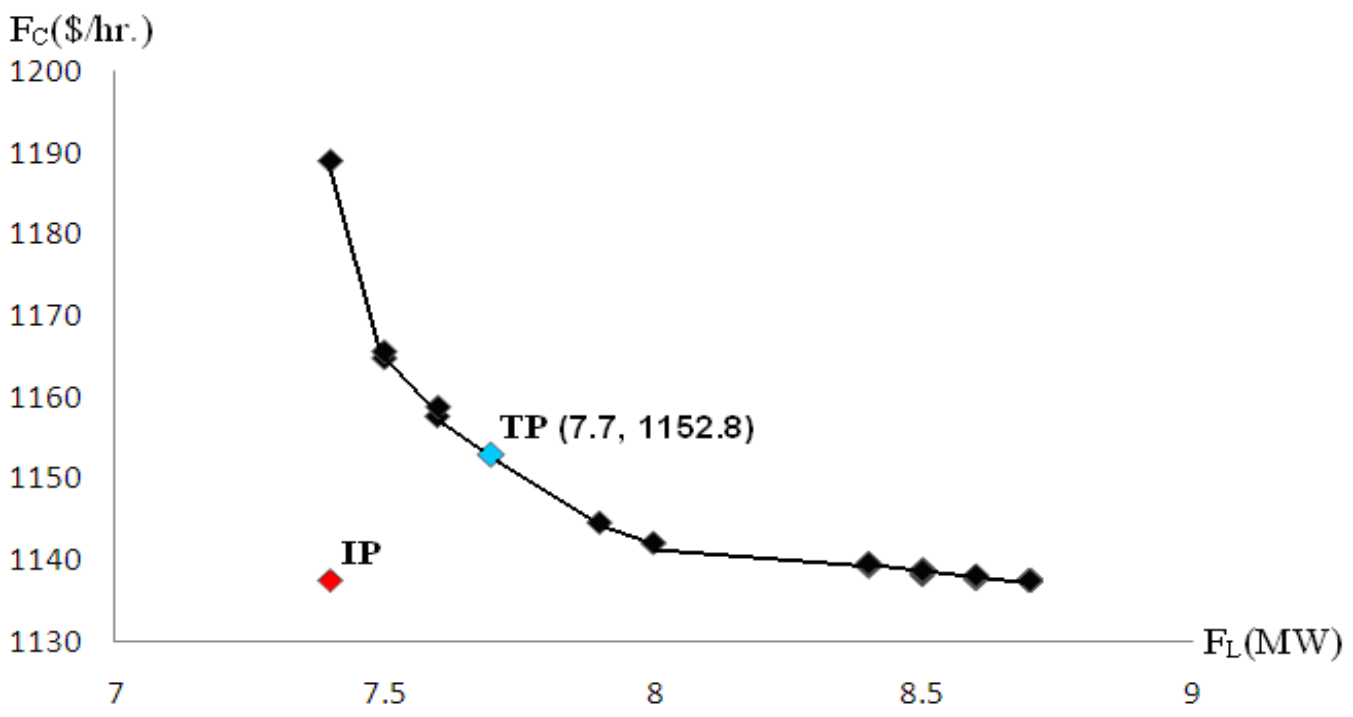

Fig.2: Noninferior set of IEEE 14-Bus system in 2D space

It is observed that at Target Point:

Cost of generation is $\mathrm{F}_{\mathrm{C}} *=1152.8 \$ / \mathrm{hr}$

Transmission losses is $\mathrm{F}_{\mathrm{L}} *=7.7 \mathrm{MW}$

Hence the Target Point is $\left(\mathrm{F}_{\mathrm{C}}{ }^{*}, \mathrm{~F}_{\mathrm{L}}{ }^{*}\right)$ or $(1152.8,7.7)$ and the minimum distance from Ideal Point $(1137.5,7.4)$ to Target Point $(1152.8,7.7)$ is 0.1937 . It is shown at S.No.10 of Table-2.

\subsection{Distance function for IEEE 30-bus system:}

From Table-3, it is observed that

$\mathrm{R}_{\mathrm{C}}=1361.2-1257.1=104.1$

$\mathrm{R}_{\mathrm{L}}=11.8-7=4.8$

$\mathrm{R}_{\mathrm{C}} / \mathrm{R}_{\mathrm{L}}=21.7$

The distance function for 30-bus is

Distance $3=\left[\left(\mathrm{F}_{\mathrm{C}}-\mathrm{F}_{\mathrm{C} \min }\right)^{2}+21.7 *\left(\mathrm{~F}_{\mathrm{L}}-\mathrm{F}_{\mathrm{Lmin}}\right)^{2}\right]^{1 / 2}$

The distance of each of the noninferior point is calculated by (11) and the result is shown in the last column of Table-3.

Table-3

Results of MOPD studies with varying weights in 2D space

(IEEE 30-bus system)

\begin{tabular}{|c|c|c|c|c|c|}
\hline S.N0. & $\mathbf{W}_{\mathbf{C}}$ & $\mathbf{W}_{\mathbf{L}}$ & $\mathbf{F}_{\mathbf{L}}$ & $\mathbf{F}_{\mathbf{C}}$ & Distance \\
\hline 1 & 0 & 1 & 7 & 1361.2 & 1.041 \\
\hline 2 & 1 & 0 & 11.8 & 1257.1 & 1.0416 \\
\hline 3 & 1 & 0.01 & 11.8 & 1257.1 & 1.0416 \\
\hline 4 & 1 & 0.05 & 11.8 & 1257.1 & 1.0416 \\
\hline 5 & 1 & 0.1 & 11.8 & 1257.1 & 1.0416 \\
\hline 6 & 1 & 1 & 11.7 & 1257.1 & 1.0199 \\
\hline 7 & 1 & 5 & 10.8 & 1260.2 & 0.8252 \\
\hline
\end{tabular}




\begin{tabular}{|c|c|c|c|c|c|}
\hline 8 & 1 & 10 & 9.8 & 1267.4 & 0.6163 \\
\hline 9 & 1 & 15 & 9.2 & 1275.4 & 0.5113 \\
\hline$\underline{10}$ & $\underline{1}$ & $\underline{20}$ & $\underline{8.7}$ & $\underline{1283.3}$ & $\underline{0.4525}$ \\
\hline 11 & 1 & 25 & 8.4 & 1290.7 & 0.453 \\
\hline 12 & 1 & 30 & 8.1 & 1297.6 & 0.4701 \\
\hline 13 & 1 & 35 & 7.9 & 1303.9 & 0.5071 \\
\hline 14 & 1 & 40 & 7.8 & 1309.8 & 0.5549 \\
\hline 15 & 1 & 45 & 7.6 & 1315.2 & 0.5954 \\
\hline 16 & 1 & 50 & 7.5 & 1320.1 & 0.6393 \\
\hline 17 & 1 & 55 & 7.4 & 1324.7 & 0.6816 \\
\hline 18 & 1 & 60 & 7.4 & 1329 & 0.7242 \\
\hline 19 & 1 & 65 & 7.3 & 1333 & 0.7618 \\
\hline 20 & 1 & 70 & 7.3 & 1336.6 & 0.7977 \\
\hline 21 & 1 & 75 & 7.2 & 1340.1 & 0.8311 \\
\hline 22 & 1 & 80 & 7.2 & 1340.1 & 0.8311 \\
\hline 23 & 1 & 85 & 7.1 & 1346.3 & 0.8923 \\
\hline 24 & 1 & 90 & 7.1 & 1349.1 & 0.9204 \\
\hline 25 & 1 & 95 & 7.1 & 1351.8 & 0.9203 \\
\hline 26 & 1 & 100 & 7 & 1354.3 & 0.9472 \\
\hline 27 & 10 & 0 & 11.8 & 1257.1 & 1.0416 \\
\hline 28 & 10 & 0.01 & 11.8 & 1257.1 & 1.0416 \\
\hline 29 & 10 & 0.5 & 11.8 & 1257.1 & 1.0416 \\
\hline 30 & 10 & 0.1 & 11.8 & 1257.1 & 1.0416 \\
\hline 31 & 10 & 10 & 11.7 & 1257.1 & 1.0199 \\
\hline 32 & 10 & 15 & 11.7 & 1257.2 & 1.0199 \\
\hline 33 & 10 & 20 & 11.6 & 1257.2 & 0.9982 \\
\hline 34 & 10 & 25 & 11.5 & 1257.6 & 0.9765 \\
\hline 35 & 10 & 30 & 11.3 & 1258 & 0.9331 \\
\hline 36 & 10 & 35 & 11.2 & 1258.5 & 0.9115 \\
\hline 37 & 10 & 40 & 11.1 & 1259 & 0.8899 \\
\hline 38 & 10 & 45 & 10.9 & 1259.8 & 0.8467 \\
\hline 39 & 10 & 50 & 10.8 & 1260.2 & 0.8252 \\
\hline 40 & 10 & 55 & 10.7 & 1260.8 & 0.8038 \\
\hline 41 & 10 & 60 & 10.6 & 1261.5 & 0.7824 \\
\hline 42 & 10 & 65 & 10.4 & 1262.9 & 0.7401 \\
\hline 43 & 10 & 70 & 10.3 & 1262.9 & 0.7184 \\
\hline 44 & 10 & 75 & 10.2 & 1263.6 & 0.6974 \\
\hline 45 & 10 & 80 & 10.1 & 1264.3 & 0.6765 \\
\hline
\end{tabular}




\begin{tabular}{|c|c|c|c|c|c|}
\hline 46 & 10 & 85 & 10.1 & 1265.1 & 0.6774 \\
\hline 47 & 10 & 95 & 9.9 & 1266.6 & 0.6364 \\
\hline 48 & 10 & 100 & 9.8 & 1267.4 & 0.6163 \\
\hline
\end{tabular}

Noninferior set for IEEE 30-bus has been shown in graph of Fig.3. It has been plotted from Table-3 between transmission loss function (as X-axis) and cost of generation function (as Y-axis). IP shows the Ideal Point which is infeasible and TP shows the Target Point or the best compromise solution which is at minimum distance from Ideal Point $\left(\mathrm{F}_{\mathrm{C}} *, \mathrm{~F}_{\mathrm{L}}{ }^{*}\right)$.

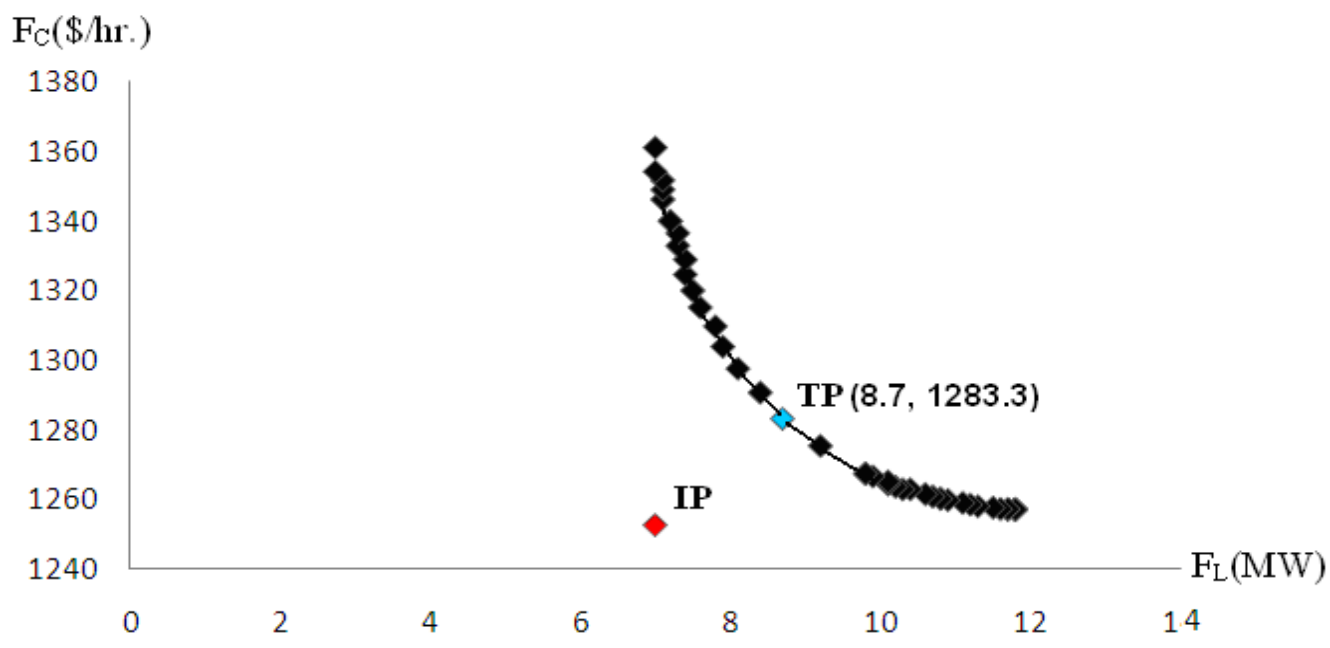

Fig.3: Noninferior set of IEEE 30-Bus system in 2D space

Observation at the Target Point:

Cost of generation is $\mathrm{F}_{\mathrm{C}} *=1283.3 \$ \mathrm{hr}$

Transmission losses is $\mathrm{F}_{\mathrm{L}} *=8.7 \mathrm{MW}$

Hence the Target Point is $\left(\mathrm{F}_{\mathrm{C}} *, \mathrm{~F}_{\mathrm{L}}{ }^{*}\right)$ or $(1283.3,8.7)$ and the minimum distance from Ideal Point $(1257.1,7)$ to Target Point $(1283.3,8.7)$ is 0.4525 . It is shown at S.No.10 of Table-3.

\section{Discussions}

From Table-1, it is observed that for IEEE 5-bus system the Target Point (TP) is achieved when $\mathrm{W}_{\mathrm{C}}=1.0$ and $\mathrm{W}_{\mathrm{L}}=20$. Similarly, for IEEE 14-bus system, the TP is achieved when $\mathrm{W}_{\mathrm{C}}=1.0$ and $\mathrm{W}_{\mathrm{L}}=40$. Also, for IEEE 30-bus system the weights at the TP are: $\mathrm{W}_{\mathrm{C}}=1.0$ and $\mathrm{W}_{\mathrm{L}}=20$. These can be considered as the optimal weights, which when attached to the objective function will give TP in single step. The optimal weights and the TP for IEEE 5-bus, 14-bus and 30-bus systems are summarized in Table-4.

Table-4

Optimal weights and Target Points

\begin{tabular}{|c|c|c|c|c|}
\hline IEEE system & $\mathbf{W}_{\mathbf{C}}$ & $\mathbf{W}_{\mathbf{L}}$ & $\mathbf{F}_{\mathbf{C}}{ }^{*} \mathbf{( \$ / h r} \mathbf{)}$ & $\mathbf{F}_{\mathbf{L}}{ }^{*}(\mathbf{M W})$ \\
\hline 5-bus & 1.0 & 20 & 761.57 & 5.0856 \\
14-bus & 1.0 & 40 & 1152.8 & 7.7 \\
30-bus & 1.0 & 20 & 1283.3 & 8.7 \\
& & & & \\
& & & & \\
\hline
\end{tabular}

The analysis of Table-4 shows that in order to achieve the Target Point (TP), $\mathrm{W}_{\mathrm{C}}$ is should be kept fixed to 1.0 where as $\mathrm{W}_{\mathrm{L}}$ should be varied from 20 to 40 . 


\section{Conclusions}

The focus of this paper work concentrates on simultaneously minimization of two objectives of power system - cost of generation and transmission loss using weighting method and Formulation of solution methods to obtain the optimum solution of Multiobjective optimal power dispatch (MOPD) problem has been implemented successfully using weighting method with the help of GA tool.

The noninferior set for IEEE 5, 14 and 30 bus systems has been obtained by parametrically varying weights attached to each of the objectives in the objective function and Target Point (TP) or best compromise solution is obtained by Minimum Distance Method.

It has been observed that Target Point for IEEE 5-bus, 14-bus and 30-bus systems can be achieved, if the weight attached to cost of generation $\left(\mathrm{W}_{\mathrm{C}}\right)$ is kept fixed to 1.0 (one), where as the weight attached to the system transmission loss $\left(\mathrm{W}_{\mathrm{L}}\right)$ is varied from 20 to 40 .

The weights at which the Target Point is achieved have been determined for IEEE 5-bus, 14-bus and 30-bus systems. These are called the optimal weights. If the optimal can be derived weights and the Target Point or the best compromise solution can achieve be in a single step which will save lot of computational effort.

It has been observed that the optimal weights in all the cases were almost equal to the ratio of $R_{C} / R_{L}$. The minimum distance technique has no limitation in handling more than two objectives.

\section{References}

[1]. Cohon, J.L., 'multiple objective programming and planning', New York, London: Academic Press, 1978.

[2]. Sawaragi, Y.; Nakayama, H. and Tanino, T. 'Theory of Multiobjective Optimization' (vol. 176 of Mathematics in science and engineering). Orlando, FL: Academic Press Inc. ISBN 0126203709, 1985.

[3]. Steuer, R.E., 'Multiple Criteria Optimization: Theory, Computations, and Application'. New York: John Wiley \& Sons, Inc. ISBN 047188846X, 1986.

[4]. M. Salami, and G. Cain, 'Multiple Genetic Algorithm Processors for The Economic Power Dispatch Problem', Proceeding of the Genetic Algorithm in Engineering Systems: Innovations and Applications, Conference Publication, pp 188-193, No. 414, IEE, 1995 .

[5]. M. Carlos, C. M. Fonseca and P. J. Fleming. 'An Overview of Evolutionary Algorithms in Multiobjective Optimization', Evolutionary Computation, vol. 3, pp. 1-16,1995.

[6]. Wadhwa C.L., Jain N.K., 'Multiple objective optimal load flow: a new perspective', 137(1):11-18, IEE Proc C 1990.

[7]. U. Nangia, N.K. Jain, C.L. Wadhwa, 'Multiobjective optimal load flow based on ideal distance minimization in 3D space', Electrical power and energy systems (23) 847-855, 2001 